\title{
Barber's Syndrome
}

\section{Can B*}

Reconstructive Aesthetic Surgery, Balikesir City Hospital, Turkey

*Corresponding author: Dr. Bilgen Can, Reconstructive Aesthetic Surgery, Balikesir City Hospital, Turkey, Tel: 053037275 82; E-mail: bdenizag@gmail.com

\section{Case Report \\ Volume 2 Issue 1}

Received Date: February 23, 2018

Published Date: March 22, 2018

DOI: $10.23880 /$ ijtps-16000111

\section{Abstract}

Barber's Syndrome is a professional and rare disease that is caused by penetration of exogenous hair particules to interdigital web spaces. Retrospectively 50 cases of interdigital pilonidal sinus have been reported but only 15 of them are pronounced as Barber's Syndrome. This problem can also be seen in dog hair dresssers, sheep or goat wool workers Case: Thirty-one years old, male patient with the complaint of painful swelling and foul - smelling discharge of a little fistula opening at 2 nd interdigital web space. Hair could be visualized in fistula tract. Patient had no benefit of using long time antibiotic medication. MRI showed us a $2 \times 1,5 \mathrm{~cm}$ mass with heterogenous content. Primary excision of the mass performed under local anesthesia. No early or late (2 years) postoperative complications reported. Results: Barber's Syndrome is pilonidal sinus of interdigital web space and can be seen at men hairdressers as a very rare professional disease. Isolated antibiotic usage shows no benefit and surgery is the only choice of treatment.

Keywords: Barber; Interdigital pilonidal sinus; Surgery

\section{Introduction}

Barber's syndrome is a plenoidal sinus that occurs in the interdigital space resulting in penetration from the epidermis by hard and short hairs. As an occupational disease, it is named like that because of its being seen in barbers [1,2].

It was first described by temptalion in 1942 as interdigital foreign body granuloma [3].

Literature review shows that less than 15 of the more than 50 cases of plenoidal sinus are barber's Syndrome [1]. Other than that, it can be seen in pet groomers and goat milk milkers [4-8].
The penetration of short and hard hairs into the epidermis and the accumulation in the interdigital space triggers infection and leads to the classic plenoidal sinus pattern. However, unlike the classical plenoidal sinus, this pattern is formed in the interdigital space free of hair follicles and with exogenous, non-patient hair [1,2,9-12].

Its clinic is sometimes painful, draining and swollen in the interdigital space. Short and hard hairs can be seen in the drainage.

Treatment is secondary recovery after surgical excision, or primary suturation, or repair with rotation flap. Antibiotic therapy alone is not enough [1-12]. 


\section{International Journal of Transplantation \& Plastic Surgery}

In this study, interdigital plenoidal sinus in a barber who underwent surgical excision and primer repair was studied with diagnosis and treatment stages.

\section{Case Report}

A 31-year-old male patient has been being a barber for 15 years. He applied to various centers with complaints of swelling and draining at 2 interdigital space for 1.5 years (Figure 1). He only had antibiotherapy and there was no regression in his complaints. In the $\mathrm{MR}$ taken at the external center, the second interdigital space shows a heterogeneous mass with a size of $2 \times 1.5 \mathrm{~cm}$ which can be clearly separated.

The patient underwent extensive excision under local anesthesia with fistula and unhealthy skin (Figures 2-4). Thick-walled cysts and short thick hairs were observed in excised material at the mouth of the fistula (Figure 5). The defect site after the excision was primary repaired. He was observed again on the postop 5th and 7th days, and on the 7th day, follow-up was taken without medical dressing. The patient had started his occupation on the postop 14th day. He was examined again in the postop $3^{\text {rd }}$ month, $1^{\text {st }}$ year and the $2^{\text {nd }}$ year. No recurrence or any complication was encountered in the patient (Figure 6).

In the pathologic examination of specimens, a superficially squamous epithelium fitted sinus tract, deep chronic inflammatory granulation tissue and numerous hair shaft were observed. In addition, foreign body granulomas developed against the hair shaft (Figures 7 \& 8).

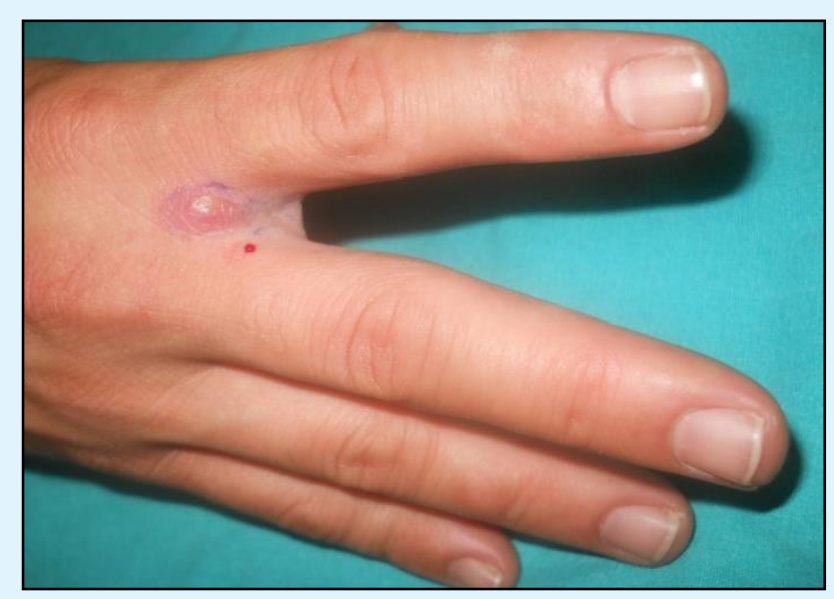

Figure 1: Swelling involving the fistula mouth in the second interdigital space.
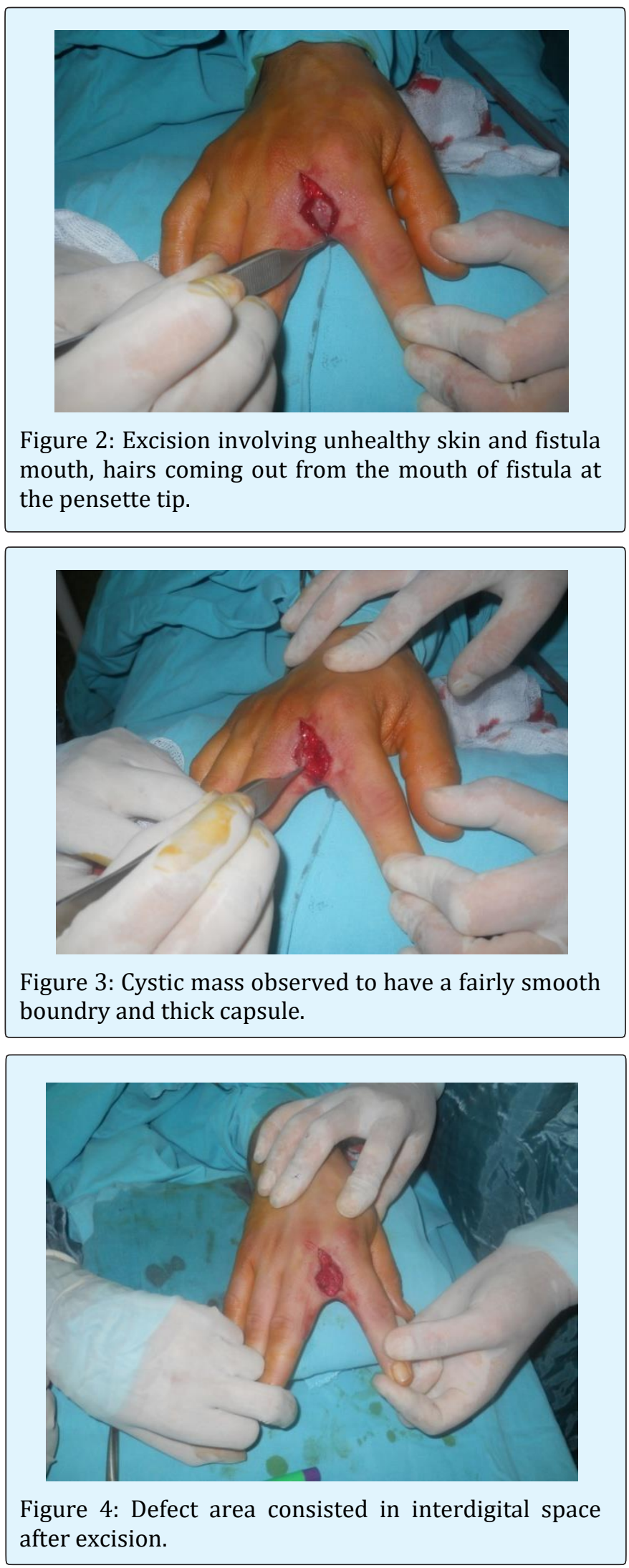


\section{International Journal of Transplantation \& Plastic Surgery}

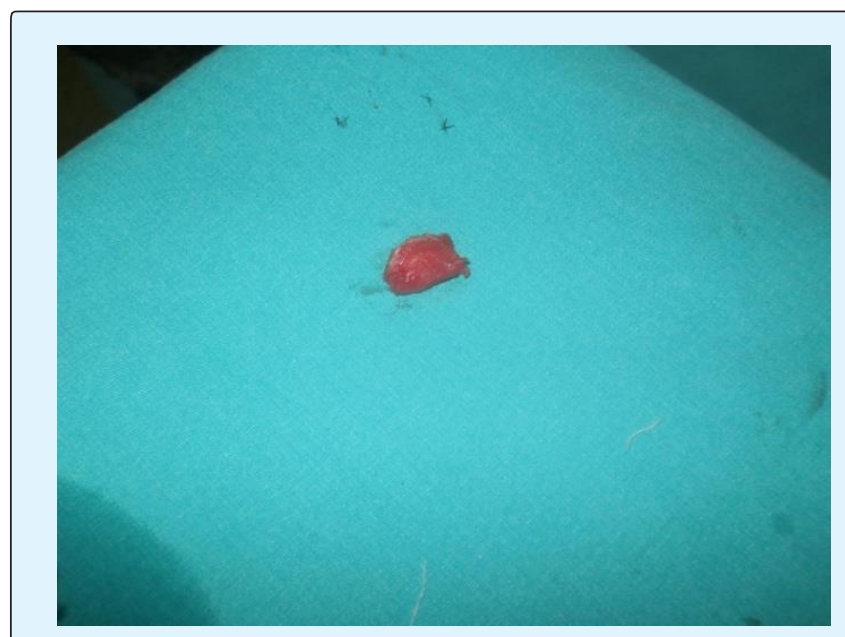

Figure 5: Excised cyst and hair scattered around.
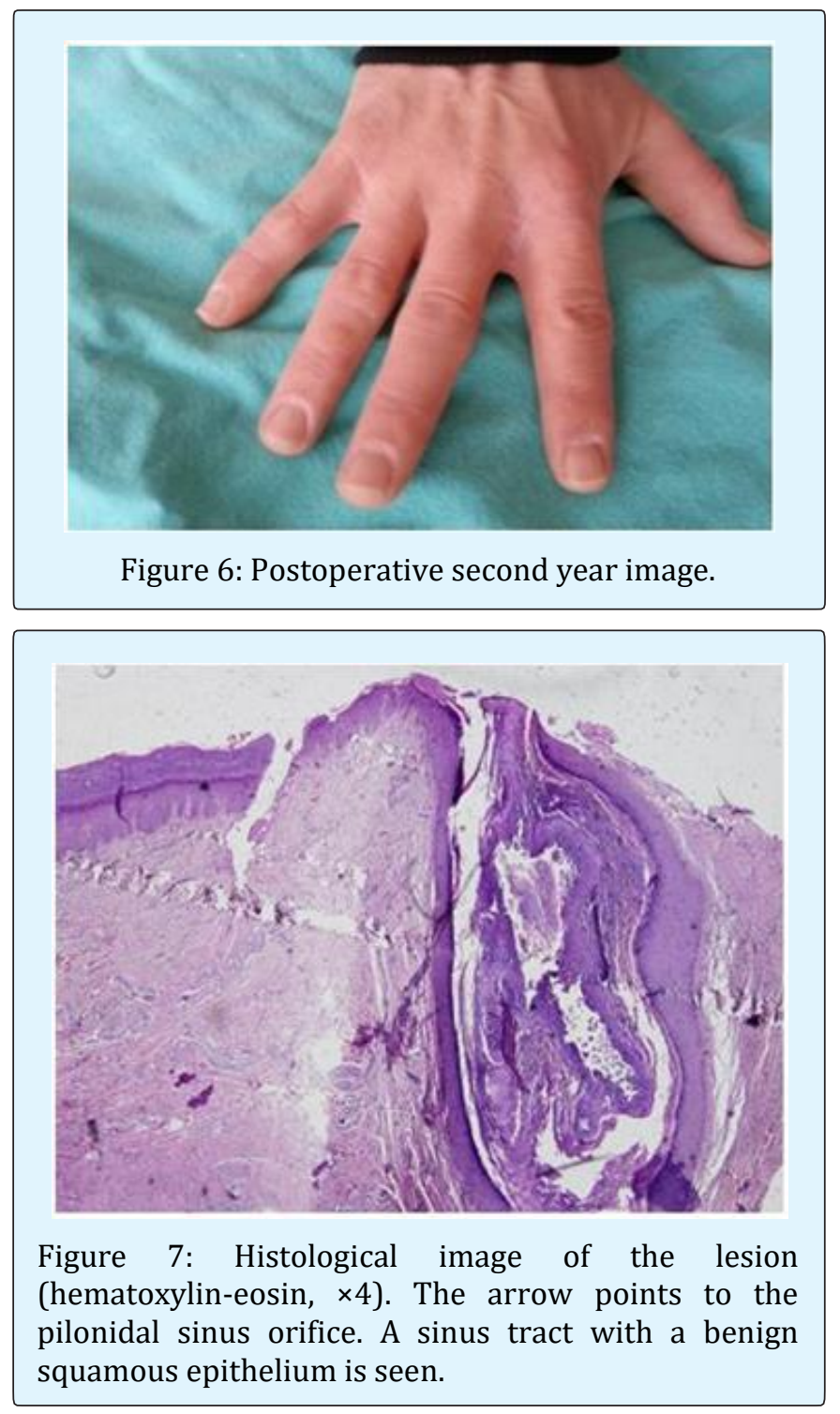

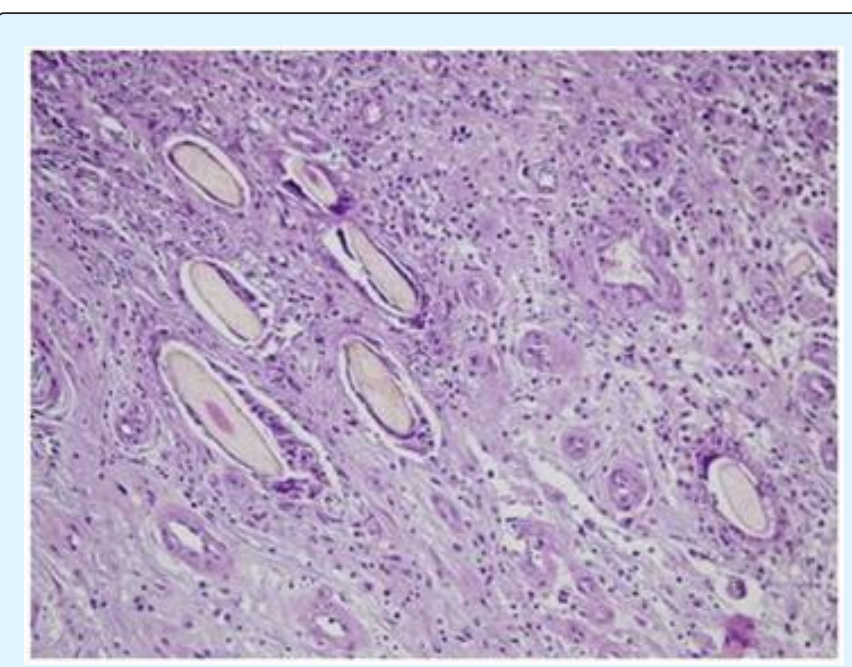

Figure 8: In chronic inflammatory granulation tissue, hair shaft (arrows) surrounded by foreign body type giant cells are seen. (H \& amp; E).

\section{Discussion}

Barber's syndrome is an interdigital plenoidal sinus that occurs in barbers as an occupational disease [1,2].

Penetration of the epidermis with short and hard hairs leads to sinus formation, hair accumulation triggers infection, leaking out through the sinus, and hair present in the drainage. Over time, as the formation is covered with the foreign body granulation texture, the cyst with exogenous hairs occurs [1,2,9-12].

The fact that it is a rare case, it has led to confusion in diagnosis and treatment. The patient applied to various centers for 1.5 years and had long-term antibiotic treatment. Isolated antibiotic therapy is not curative for the plenoidal sinus [1-10]. Antibiotics are used in the presence of active pre-surgical infection, for the eradication of infection, or prophylactically in the postoperative term $[8,9]$.

Fistulography can be performed to determine the depth of the cyst before surgery [1]. As in the classic plenoidal sinus, the width of the surgery can be determined perioperatively with methylene blue injection [12]. Since the lesion content, size, and healthy tissue differentiation can be determined clearly, ultrasonography is also used to assist the diagnosis and in determining the width of the surgery.

We benefited from the MR that our patient had in the external clinic. However, we did not find a case in the literature that used MR for diagnostic purposes or to 


\section{International Journal of Transplantation \& Plastic Surgery}

determine the width of the surgery. We think that other methods evaluating preoperative size and spread are more cost-effective.

After excision of the plenoidal sinus, repair can be performed by leaving for secondary recovery, primary suturation or rotation flap. There is no definite rule about which treatment to choose. Of course, the size of the defect, the condition of the wound and the likelihood of recurrence should be considered. It has been noted that recurrence is less visible in cases which were left for the secondary recovery $[1,2,9-12]$. This may be due to the fact that the scar tissue formed by the secondary recovery constitutes a stronger barrier for penetration of the hair in the interdigital space.

After the cystine excision, we reached the clean and healthy tissue on the base and primary repair was performed in the defect area. We did not encounter any complications in the follow up to the early period and the second year.

\section{Conclusions}

Interdigital plenoidal sinus is a rare occupational disease. It can be seen in sheep breeders, goat wooleners and barbers. It is called barber syndrome when it was seen in barbers. It manifests itself as a cyst which is painful, draining, and in which the hair can be seen at the mouth of fistula in the interdigital space. Fistulography and USG can reveal cyst size. The width of the surgery can be determined by perioperative methylene blue injection. It is resistant to isolated antibiotic treatment. The only treatment is surgical excision. Repair can be performed by leaving the secondary recovery after excision, primer suturation or rotation flap.

\section{References}

1. Uysal AC, Alagöz MS, Unlu RE, Şensoz O (2003) Hair Dresser's Sydnrome: A case report of interdigital plenoidal sinus and rewiev of the literature. Dermatol Surg 29(3): 288-290.
2. Patel MR, Bassini L, Nashad R, Anselmo MT (1990) Barber's İnterdigital Pilonidal Sinus of the Hand: a foreign body hair granuloma. J Hand Surg Am 15(4): 652-655.

3. Templeton H (1942) Foreign Body Granuloma or Interdigital Cyst with Hair Formation. Archives of Dermatology and Syphilology 46: 157-158.

4. Papa CA, Ramsey ML, Tyler WB (2002) Interdigital pilonidal sinus in a dog groomer. J Am Acad Dermatol 47(5): S281-282.

5. Mohanna PN, Al-Sam SZ, Flemming AF (2001) Subungual pilonidal sinus of the hand in a dog groomer. Br J Plast Surg 54(2): 176-178.

6. Menenghini CL, Gianotti F (1964) Granulomatosis fistulosa interdigitalis of milkers' hands. Dermatologica 128: 38-50.

7. Phillips PJ (1966) Web space sinus in shearer. Med J Aust 2(24): 1152-1153.

8. Vaiude P, Dhital M, Hancock K (2011) A true pilonidal sinus in the hand of a sheep shearer. JSCR 12: 6 .

9. Hueston JT (1951) Pathology of the interdigital pilonidal sinus. Aust N Z J Surgery 21(3): 226-229.

10. Joseph HL, Gifford H (1954) Barbers' interdigital pilonidal sinus. Arch Dermatol Syphilol 70(50): 616624.

11. Powell HDW (1955) Interdigital sinuses in barber's hand. Br J Surg 43: 520-521.

12. Uysal AC, Orbay H, Uraloglu M, Sensoz O, Hyakusoku $\mathrm{H}$ (2007) A rare occupational disease of hair dressers: Interdigital pilonidal sinus. J Nippon Med Sch 74(5): 364-366. 